\title{
OS CAMINHOS DA IDENTIDADE: ANTROPOLOGIA E HISTÓRIA NO SERTÃO DE ALAGOAS
}

BRISA PIRES MOURA ${ }^{1}$

UFRGS, BRASIL

\section{RESENHA}

BEZERRA, Deisiane da Silva, PEIXOTO, José Adelson Lopes, ROCHA, Adauto Santos da. (Orgs). Memória e identidade indígena em Alagoas. Maceió, AL: Editora Olyver, 2020.

A ligação entre antropologia e história não é novidade para ambas as disciplinas e tem ao longo de muito tempo proporcionado a elaboração de pesquisas sobre temas diversos. Aqui, por exemplo, temos a resenha de uma coletânea de artigos nos quais, em muitos momentos, é proposta a utilização de uma Antropologia histórica para que se compreendam processos ligados à memória e ao processo de construção de identidade de comunidades indígenas do sertão alagoano.

Algo importante de mencionar sobre a publicação é a ausência de autores estrangeiros vindo estudar e desenvolver trabalhos sobre comunidades indígenas do Nordeste. Embora a presença deles não se configure como um problema, parece simbólico que tais textos tenham privilegiado a presença de autores que ou residem nas proximidades ou são membros das próprias comunidades das quais os artigos tratam. Ainda para fins de contextualização sobre as condições de produção do trabalho, é importante abordar também a formação acadêmica dos autores, pois boa parte deles, se não sua totalidade, são historiadores que se interessam pelo que é chamado de nova história ou micro-história, ou seja, não se dedicam a construir suas pesquisas apenas através de fontes documentais, mas também levam em conta um contexto maior ao redor: assim como nos trabalhos antropológicos, as narrativas, as histórias e o campo externo no geral passam a ser objetos de interesse ao olhar historiográfico - aspecto este enfatizado no prefácio do livro:

\footnotetext{
${ }^{1}$ Mestranda em Antropologia Social (Universidade Federal do Rio Grande do Sul, Brasil). E-mail: brisapiresmoura@gmail.com.
} 
vinculam-se às abordagens da chamada "nova história indígena" que a partir da década de 1990 vem discutindo e evidenciando os protagonismos sociopolíticos dos indígenas na História do Brasil. Buscando superar visões deterministas que enfatizavam os índios como vítimas diante do avassalador processo apenas inicial da colonização portuguesa, são pesquisas históricas que, principalmente em importantes diálogos com a Antropologia e também outras áreas do conhecimento, vem contribuindo decisivamente nas discussões para repensar os papéis e lugares dos indígenas em diferentes espaços e períodos ao longo da história do nosso país (BEZERRA et al., 2020, p. 16).

"Memória e identidade indígena em Alagoas" é composto por um conjunto de treze artigos, escritos por membros do Grupo de Pesquisas em História Indígena de Alagoas - GPHIAL. Sediado na Universidade Estadual de Alagoas (UNEAL), o grupo articula, prioritariamente, as temáticas da história, imagem, cultura, memória, etnografia e território ao campo indigenista e está em atuação desde 2009 sob esta designação, embora sua trajetória no desenvolvimento de pesquisas sobre as comunidades indígenas no estado de Alagoas seja anterior à sua formalização como grupo de pesquisa.

A região onde se encontra o campus da Universidade motivou a criação do grupo de pesquisa. Embora a área do município de Palmeira dos Índios contasse com a presença de sete comunidades indígenas, uma boa parte da população externa às comunidades não reconhecia ou percebia a participação desses grupos no surgimento e desenvolvimento da cidade.

A coletânea de textos foi selecionada por José Adelson Lopes Peixoto, coordenador do grupo e um dos organizadores da publicação, e contempla os melhores trabalhos desenvolvidos pelos membros do grupo. Os treze artigos são divididos em três grandes partes, cada uma delas destinada a falar sobre um dos três povos os quais o livro aborda. Assim, a Parte I trata do povo Xucuru-Kariri; a Parte II que traz questões sobre o povo Tingui-Botó; e a Parte III reflete sobre o povo Jiripankó. Embora partilhem temáticas gerais comuns (antropologia histórica, etnicidade, memória) os textos apresentam grande pluralidade em suas temáticas mais especificas, traço este que tem estreita correlação com as distintas formações dos seus autores.

No que se refere à discussão dos artigos da coletânea, o texto que abre a primeira parte do livro recebeu o título de "XUKURU-KARIRI: política, mobilizações e conquistas na segunda metade do século XX". De autoria de Adauto Santos da Rocha e Edson Silva, o trabalho aborda os processos e negociações políticas pelos quais tal comunidade indígena passou no decorrer período informado no título. Segundo o autor, antes de se organizarem politicamente, os indígenas vagavam pela região em subempregos nas fazendas da região. A conquista da terra foi o resultado de muitas mobilizações que envolveram a persistência da comunidade, 
além de negociações com órgãos governamentais, apoio de outros povos indígenas e disputas com políticos e empresários locais.

Em seguida temos o trabalho "Assembleias indígenas: espaços discursivos e de fortalecimento cultural e político do povo Xukuru-Kariri em Palmeira dos Índios/AL (2011-2013)" de autoria de Amanda Maria Antero da Silva. Nessa pesquisa, a autora descreve o papel e a importância das assembleias indígenas para que a comunidade se mantenha resistindo e adquirindo melhorias para todos. Para a autora, as assembleias são momentos nos quais, além do eminente papel político desses espaços (organização de demandas, administração de problemas e conflitos), também é de extrema importância para o fortalecimento dos sentimentos de pertencimento e coletividade entre os membros do grupo.

Já em "Silenciamento e emergência: os Xucuru-Kariri em Palmeiras dos Índios/AL-1821/1962"), de Brunemberg da Silva Soares, o autor busca compreender a questão do silenciamento perpetrado a essas populações que, em um momento oportuno, foi assimilado pelos indígenas enquanto uma estratégia de resistência para que estes pudessem, finalmente, emergirem politicamente como Xucuru-Kariri. $\mathrm{O}$ autor afirma que a comunidade viveu esse período "procurando adaptarse às novas situações, reelaborando costumes, silenciando práticas e socializando memórias e experiências que foram afirmadas posteriormente" (SOARES, 2020, p.54).

Como boa parte dos textos escritos na coletânea foram escritos por historiadores, a ênfase maior recai sobre ao passado, embora alguns textos proponham articulações como o panorama contemporâneo, como no caso de "Políticas, estratégias e alianças: processos de reconhecimento étnico no Nordeste e o caso Xukuru-Kariri (1921-1952)", escrito por Deisiane da Silva Bezerra, que analisa o contexto histórico e político de um ponto de vista macrossocial e, através de um olhar para o contexto nacional, objetiva compreender como os Xucuru-Kariri se mobilizaram em busca de seus direitos.

Também merece destaque o trabalho de Luan Moraes dos Santos, pois nos permite refletir como algumas produções literárias podem contribuir para a construção e divulgação de uma imagem negativa dos povos indígenas por intermédio do acionamento de representações simplistas de tais povos no interior dos enredos das narrativas. Em seu trabalho intitulado "Gracilianismo das Elites: A forja ideológica de um conflito", Luan trata do impacto negativo presente na obra do conhecido escritor Graciliano Ramos, visto que este produziu um retrato pejorativo e exotizado do povo Xucuru-Kariri que teve, como consequência tangível, a ampliação da dificuldade por parte destes nativos no processo de retomada de suas terras. Longe de ser um processo sem precedentes, a problemática articulação entre representações desfavoráveis dos indígenas e fragilização da mobilização política também está presente na obra The Fierce People" de autoria do antropólogo norte-americano Napoleon Alphonseau Chagnon (1968). Segundo este autor, a construção e consolidação de um estereótipo negativo dos Yanomami, disseminado até hoje por canais de informação sensacionalistas, tende a retratar tal população como violenta por natureza, o que influencia diretamente na 
menor obtenção de direitos que tal parcela da população disfruta em seu país.

Já em "Toré: ritual identitário de autoafirmação cultural do povo Xukuru-Kariri", Maria Aparecida Oliveira dos Santos e Ricardo José Lima Bezerra analisam a importância do Ritual da Toré para a população Xukuru-Kariri enfatizando tanto seu papel como importante ferramenta de afirmação identitária para essa população, quanto mostrando o caráter estigmatizado de tal prática pela população não indígena da região, resultando na materialização série de perseguições e preconceitos contra tais nativos.

Uma vez que o direito a terra é um dos aspectos mais importantes para as populações indígenas é, portanto, amplamente mencionado em diversos trabalhos, pois é através dela que tais populações buscam sua subsistência, fato este que justifica suas lutas. Em "Xukuru-Kariri: Terra, educação e saúde na Aldeia mata da Cafurna", de Maria Regineide Gomes Carvalho, a pesquisadora analisa o quanto a questão da terra para os Xucuru-Kariri vai muito além de aspectos como moradia e provisão de alimentos para mostrar a centralidade da terra na configuração do próprio modo de vida dessa população. Desta forma, a autora assinala que:

Incluso a esse conceito "terra", estão inseridas outras demandas, tais como a educação e saúde de forma diferenciada que atenda suas necessidades, respeitando as expressões socioculturais e modo de vida desses povos (CARVALHO, 2020, p. 97).

Ainda sobre o povo Xukuru-Kariri e lidando com a questão do território, embora desta vez tratando a relação entre a luta pela terra e os processos de construção da identidade da população da região, temos "Memórias do povo Xukuru-Kariri: o ambiente como uma construção identitária" de Mary Hellen Lima das Neves, texto que enfatiza a importância da história oral para reduzir as lacunas da história de modo a questionar a narrativa historiográfica produzida e usualmente acionada pelas elites e a conferir voz, através do relato das próprias memórias, ao discurso de pessoas até então invisibilizadas.

Nos trabalhos que falam sobre a questão das identidades indígenas no Nordeste, é recorrente que haja momentos de questionamentos e conflitos acerca da veracidade ou validade das identidades de membros desses grupos. Em "Identidades em conflito: os Xukuru-Kariri aldeados e desaldeados", de Robson Romildo de Melo Vieira, uma nova dimensão desses questionamentos é acionada, qual seja, a problemática dos indígenas que, apesar de se reconhecerem e serem reconhecidos como tal, não se encontram mais residindo dentro dos limites da terra dos Xucuru-Kariri, mesmo que realizem visitas frequentes e continuem participando das ritualizações junto ao restante dos membros do grupo.

O trabalho de Robson Vieira nos fornece os desdobramentos dessa saída da comunidade, mostrando como isso não é bem visto por alguns indígenas e, muitas vezes, acarreta uma sensação de vergonha 
para aquele que escolheu ou teve de sair por alguma questão pessoal. É interessante observar que o autor do texto é membro da comunidade em questão e se coloca como crítico dos Xucuru-Kariri "desaldeados", independentemente da causa pela qual saíram. Essa posição fica evidente quando o autor afirma que:

Hoje, os descendentes dos "grandes guerreiros" da outrora poderosa nação Xukuru-Kariri que dominara vastas planícies e serras cobertas por florestas, banhadas por rios dos quais só restam os nomes, e das florestas, pequenas reservas, travam uma batalha interna e externa para manter sua tradição e fazer valer seus direitos, mesmo tendo em seu seio alguns poucos que negam a sua própria cultura e identidade e não reacendem a chama de suas tradições, optando por uma vida na cidade, muitas vezes escravizados pelo capital que impera naquele meio (VIEIRA, 2020, p. 131).

Embora o trabalho nos traga informações bem interessantes sobre a perspectiva de um indígena graduado em História acerca da maneira segundo a qual concebe sobre sua própria comunidade, talvez seja importante lembrar que, historicamente, como reforçam outros textos contidos na presente coletânea, a própria população Xucuru-Kariri teve de se submeter e se dispersar. Naturalmente, o que se pretende com esta observação não é deslegitimar o posicionamento do autor sobre tal questão, mas apenas chamar a atenção para a importância de se considerar as visões e motivações dos desaldeados que balizam a decisão por parte deles em deixar de residir dentro dos limites do território do grupo.

Na segunda parte do livro, que se propõe a falar sobre o povo Tingui-Botó, há apenas um único artigo intitulado: "Rio de Areia": O Boacica e o equilíbrio ambiental em seu entorno, escrito por Marcelo de Campos. O texto aborda a situação de assoreamento do Rio Boacica, rio muito importante para o povo Tingui-Botó, incluindo sua importante dimensão ritualística, sobretudo no que diz respeito ao ritual do Ouricuri. O trabalho também ressalta o papel que a comunidade desempenha na tentativa de preservação do meio ambiente e do rio, que se encontra cada vez mais assoreado - processo este entendido pela comunidade como "morte do rio" e que cada vez mais traz dificuldades aos mais diversos âmbitos do grupo.

Eis então que entramos na terceira parte da coletânea, que trata do povo Jiripankó e se inicia com o trabalho "Universo encantado Jiripankó: dádiva e reciprocidade", no qual José Adelson Lopes Peixoto apresenta conceitos clássicos da antropologia, como os de dádiva e reciprocidade na perspectiva de Marcel Mauss, para debater a realidade Jiripankó. José Peixoto relaciona a obra de Mauss com a dinâmica do pagamento de promessas entre os Jiripankó:

A dinâmica que compõe o universo ritual dos Jiripankó é assentada em um sistema de trocas para com os 
Encantados, que recebem oferendas em reconhecimento pela realização das curas de enfermidades ou pelos ensinamentos apontados para sanar problemas difíceis ou infortúnios. É uma relação que Mauss define como prestações e defende que "as prestações primitivas revestem a forma de dádivas, de presentes, reguladas por três obrigações interligadas: dar, receber, retribuir". Nessa concepção, os Encantados recebem o pedido, concedem a cura e os indígenas retribuem, gerando um conjunto de retribuições mútuas que ligam os homens às suas divindades (PEIXOTO, 2020, p.150).

Assim, o autor observa na realidade dos Jiripankó características que se encaixam na nos conceitos propostos pelo etnólogo francês. Peixoto, ainda alicerçado em Mauss, enfatiza que todo esse sistema serve para fortalecer os laços e o sentimento de pertencimento entre os membros da comunidade. Essa opção por observar características de uma população do nordeste do Brasil da mesma maneira que um etnólogo francês interpretou as populações que se constituíram como corpus de seu trabalho, em muitos momentos pode nos fazer questionar sobre nossa tendência de, assim como disse Roy Wagner (2010), "chegar em campo com nossa escova de dentes e romances favoritos". Contudo, essa crítica só poderia ser realmente concretizada se tivéssemos de fato acesso ao campo e conhecêssemos a realidade e o cotidiano dos Jirinpankó, como fez o autor do artigo.

O trabalho seguinte é uma parceria entre José Peixoto, autor do artigo anterior, e Vinícius Alves de Mendonça intitulado "Pintura corporal e história indígena: cultura, narrativas e representações entre os Jiripankó - Alagoas". O trabalho reflete sobre as pinturas corporais Jeripankó e os usos e concepções diversos que esta tem dentro da cultura de tal população, na qual as marcas no corpo seriam de uso obrigatório para a realização de duas práticas rituais, a saber, a "Menino do Rancho" e "Festas do Umbu - a primeira trata da cura de crianças e a segunda da festa que celebra o início do calendário religioso do grupo.

Finalizando a coletânea temos mais um trabalho que conta com a presença de José Peixoto, desta vez em coautoria com Yuri Franklin dos Santos Rodrigues, chamado "Idas e voltas: Religião, identidade e fronteira étnica no Sertão alagoano entre o povo Jiripankó". O trabalho tem como objetivo abordar um grande processo de reelaboração religiosa e identitária de importância central para o fortalecimento do autorreconhecimento desta população indígena.

Tentar elaborar um resumo ou uma visão geral de uma coletânea que reúne uma variedade tão grande de ideias e temas, além de tratar de realidades de diferentes períodos históricos de mais de um povo é, sem dúvidas, um desafio. Fica claro que o limite de espaço e tempo aqui dispostos não nos permite explicitar todas as questões pertinentes para que se entenda toda a complexidade dos trabalhos aqui mencionados. Portanto, o presente texto configura-se como um breve relato para instigar o leitor a se interessar em conhecer mais sobre estas três populações indígenas do sertão alagoano. 


\section{Referências Bibliográficas}

CHAGNON, Napoleon. Yanomamö: The Fierce People. New York: Holt, Rinehart and Winston, 1968.

OLIVEIRA, João Pacheco (org). A viagem de volta: etnicidade, política e reelaboração cultural no Nordeste indígena. 2 ed. Rio de Janeiro: Contra Capa Livraria/LACED, 2004.

WAGNER, Roy. Existem Grupos Sociais nas Terras Altas de Nova Guiné? Cadernos de campo, São Paulo, n. 19, p. 237-257, 2010

Recebido em: 19/06/2020 * Aprovado em: 25/06/2020 * Publicado em: 11/09/2020 